Document downloaded from:

http://hdl.handle.net/10251/156102

This paper must be cited as:

Mulema, SA.; Carrión García, A. (2019). Monitoring of an aquatic environment in aquaculture using a MEWMA chart. Aquaculture. 504:275-280.

https://doi.org/10.1016/j.aquaculture.2019.01.019

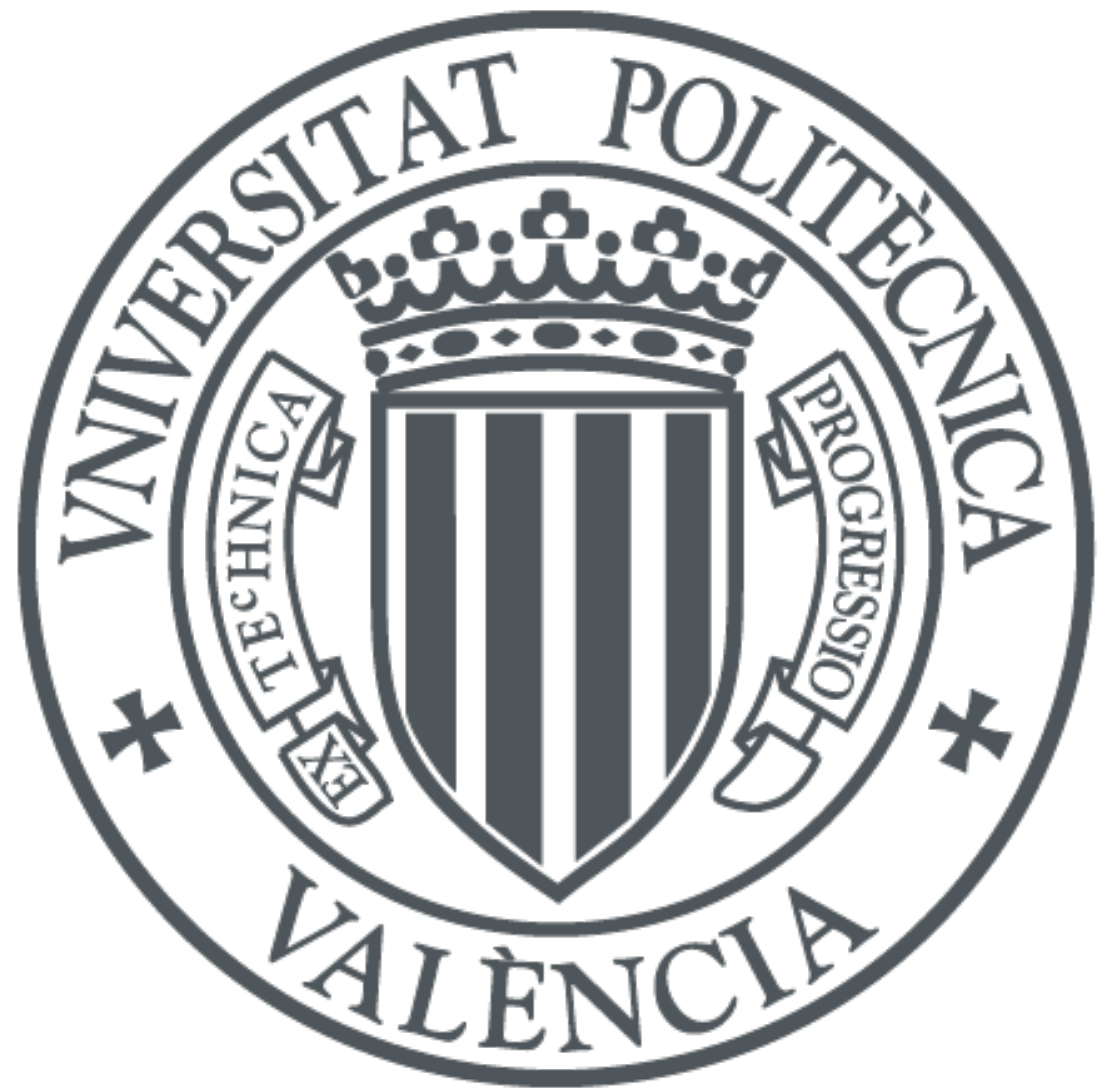

The final publication is available at

https://doi.org/10.1016/j.aquaculture.2019.01.019

\title{
Copyright Elsevier
}

Additional Information

Systematic reproduction and distribution, duplication of any material in this paper for a fee or for commercial purposes, or modifications of the content of this paper are prohibited. 


\title{
Monitoring of an aquatic environment in aquaculture using a MEWMA chart
}

\author{
S.A. Mulema ${ }^{a, *}$, A. Carrión García ${ }^{b}$ \\ a Universidade Pedagógica de Mozambique, Campus Coalane, nr. 1621, CP 106, Quelimane, \\ Mozambique \\ b Universitat Politecnica de Valencia, Camino de Vera s/n, 46022 Valencia, Spain \\ * Corresponding author. E-mail address: sermu@posgrado.upv.es (S.A. Mulema).
}

Published in: AQUACULTURE

CITE AS: S.A. Mulema, A. Carrión García,Monitoring of an aquatic environment in aquaculture using a MEWMA chart. Aquaculture, Volume 504, 2019, Pages 275-280, ISSN 0044-8486, https://doi.org/10.1016/j.aquaculture.2019.01.019.

\begin{abstract}
A B S T R A C T
Monitoring an aquatic environment in aquaculture is usually carried out by controlling its physicochemical and biological parameters. The global state of the process is evaluated though the individual conditions shown in each parameter. However, the correlation structure in the data, caused by interdependence between these parameters, provides relevant information which must be controlled. Thus, the complex structure of the data requires a multivariate control method to explore both the individual and interactive effects of the environ- mental parameters. To achieve this goal, this paper presents a statistical method based on a Multivariate Exponentially Moving Average (MEWMA) chart to monitor the multivariate structure of an aquatic environment in aquaculture, especially in a crop of tilapia in Mozambique. The results show that the adjusted MEWMA chart is more consistent when controlling the conformity and stability of environmental parameters. Therefore, it can be considered an efficient statistical method to monitor an aquatic environment in aquaculture.
\end{abstract}

\section{Keywords:}

Aquaculture; Environmental parameters; Correlation structure; MEWMA chart; ARIMA model.

\section{Introduction}

The activity of breeding fish and other aquatic organisms dates back to ancient times, when man began to optimise fish production criteria for subsistence. Aquaculture production implies human intervention in the breeding process to obtain better results. Modern industrialised aquaculture has a marked significant scientific and technical compo- nent and is related to various disciplines such as biology, engineering and economics. Breeding tilapia, for example, is an activity that needs regular controls and comprehensive monitoring. The quality of a spe- cies in aquaculture depends to a large extent on the quality of water to which it is exposed. According to Martinez (Martinez, 2006), water quality is determined by its physicochemical properties such as oxygen, $\mathrm{pH}$, temperature, salinity, alkalinity, ammonium, nitrate, nitrite, phosphorus, transparency, and silicon, which must be kept under con- trol to guarantee good breeding. A mismatch of the physicochemical parameters affects the aquatic environment, causing crises that can lead to death (Alves and Mello, 2007).

Major advances are currently being made in research on methods to monitor an aquatic environment. These methods mainly focus on the improvement of technology to guarantee quality process data in real time. Some examples of recent research include the study by Zhou and Xing (Zhou and Xing, 2013), which applied a smart monitoring system to aquaculture based on hardware and software to control the industrial aquaculture process, and the 2014 paper by Yan and Shi (Yan and Shi, 2014) that presented a combination of technologies for the intelligent breeding of aquatic species, consisting of analysing the environmental 
factors which affect the growth of a species, in the search for a better environment for cultivation. In turn, $\mathrm{Xu}$ and Zhang ( $\mathrm{Xu}$ and Zhang, 2014) developed a method based on the Android platform using a system with many sensor nodes, recognising the environmental para- meter values $(\mathrm{pH}$, temperature, oxygen, water level) and transforming them into digital data. In 2015, Jinfeng and Shun (Jinfeng and Shun, 2015) developed a method for the management and cultivation of marine species based on computer technology. He proposed a system to monitor water quality based on digital technology known as ZigBee. The system collects and transmits data, records the water quality parameters (temperature, oxygen dissolute, $\mathrm{pH}$, water level) and con- trols the increase of the oxygen. In 2016, Liu et al. (Liu et al., 2016) proposed a user-friendly water monitoring system, as well as a server for storing and analysing the monitored data.

The abovementioned methods guarantee the quality of real-time process data. However, the techniques currently used in water quality monitoring are based on univariate methods, which consist of mea- suring each parameter over time and verifying their conformity through theoretical limits. The data structure of the aquaculture process is very complex, presenting a significant correlation between variables (phy-sicochemical parameters) and autocorrelation in the observations caused by time dependence. Therefore, it is not appropriate to decide on the overall state of the process based solely on the individual conditions of the parameters.

Monitoring an aquatic environment in aquaculture is more than registering and observing the compliance of conformity conditions to each physicochemical parameter. A multivariate process can show that all the variables separately are within control limits, while the corre- lation between them could be out-of-control; or vice versa.

In a statistical approach, it is not coherent to analyse each physi- cochemical parameter separately and to consider the independence of the observations, since the process information originated by the in- teraction between the parameters and the time dependence is not modelled. This work aims to apply a multivariate statistical monitoring method which enables the evaluation of the water quality environment by exploring the overall variability of physicochemical parameters. Martinez et.al (Martínez et al., n.d.) analyzed the variability of physi- cochemical and biological parameters in the coastal waters of the Murcia region through a factor and principal component analysis; and Zhou et al. (Zhou et al., 2014) applied multivariate statistical methods to describe the composition and abundance of micro-invertebrates and their relationship with the aquatic environment. However, these studies do not show how the joint variability of parameters can influence water quality, and how the dependence on observations can affect monitoring process decisions. This paper analyses the complex data structure and suggests an appropriate statistical method to monitor the aquatic en-vironment in the tanks of tilapia cultivation in Mozambique.

The quality environment in aquaculture is characterised by a set of parameters which change their properties over time. The dependence between parameters and observations implies the presence of data correlation and autocorrelation. Thus, the MEWMA chart developed to control the multivariate and autocorrelated data can be used.

In this study, four physicochemical parameters that characterise the aquatic environment were considered: dissolved oxygen, temperature, $\mathrm{pH}$ and transparency. These parameters are described below:

Dissolved oxygen is considered to be the most important physico- chemical parameter in the cultivation of aquatic species (Alves and Mello, 2007). Oxygen variations in aquaculture produce important changes in the process. According to Martinez, (Martinez, 2006), the recommendable range of oxygen for the cultivation of tilapia is $5.0-9.0 \mathrm{mg} / \mathrm{l}$. Aquatic species exposed to low oxygen levels are sus- ceptible to decreases in their rate of growth, increases in their feed/ weight gain ratio, lethargy, susceptibility to diseases and the reduction of their reproductive capacity (Nicovita, 2002). The Mozambique ti- lapia (Oreochromis mossambicus) has an advantage compared to other species because it can withstand low concentrations of dissolved oxygen of $0.1 \mathrm{ppm}$ for short periods (Russell and Thuesen, 2012). However, a lack of control of this parameter can drastically affect the productivity of this species.

Temperature is one of the parameters that limits a large variety of biological processes (Alves and Mello, 2007). Fish and shrimps are poikilothermic animals (their internal temperature depends on the environmental temperature) and are sensitive to changes in temperature (Nicovita, 2002). Unlike mammals and birds, their internal temperature is not regulated. Thus, the environmental temperature has a significant effect on the growth, feeding rate and metabolism of these animals. Poikilothermic animals are subordinated to their environment (Alves and Mello, 2007), since their activity and survival are permanently

dependent on the habitat temperature. The temperature range for cultivating tilapia is $28-32^{\circ} \mathrm{C}$, with a tolerance of up to $5^{\circ} \mathrm{C}$ below this optimum range (Alves and Mello, 2007). It is considered extremely important to ensure that the temperature levels are kept within their tolerance limits to ensure good breeding. Oreochromis mossambicus stop growing at temperatures below $16^{\circ} \mathrm{C}$. For Oreochromis niloticus the minimum lethal temperature is $12^{\circ} \mathrm{C}$, whilst Oreochromis aureus tolerates relatively low temperatures 
compared to most tilapia species, with a minimum lethal temperature of $8^{\circ} \mathrm{C}$ (Lucas and Southgate, 2003).

$\mathrm{pH}$ has a significant effect on the metabolism and physiological processes of all aquatic organisms, as well as influencing many chemical processes, such as the availability of nutrients that are directly related to primary productivity. $\mathrm{pH}$ is the concentration of hydrogen ions $(\mathrm{H}+)$ in water, indicating its degree of acidity or alkalinity. Alves and Mello (Alves and Mello, 2007) considered that the ideal pH for tilapia cultivation is 7-9. $\mathrm{pH}$ values outside this range cause changes in the behaviour of the fish, such as lethargy, growth retardation and re- production problems.

Nurseries with very transparent waters have little phytoplankton, which indicates a limited amount of natural food for tilapia, and this parameter is an important indicator to control food intake in the tilapia cultivation process. Good production of tilapia requires an ideal water transparency level of $30-50 \mathrm{~cm}$. Although nitrogen content, and nitrite and chemical oxygen de- mands are some of the limiting factors in aquaculture, these parameters were not considered in this work. The objective of this research is to show how the monitoring of the aquatic environment in aquaculture can be carried out by modelling the structure of the data using a multivariate statistical method, applied to the abovementioned parameters. Nevertheless, this does not limit the use of the method applied to any particular set of environmental parameters, since these can be quantified.

\section{Material and methods}

The database used in this work was obtained in the physicochemical parameter registration process in the company Aquapesca de Mozambique. The cultivation of tilapia was carried out in brackish water, with $30 \mathrm{~g} / \mathrm{kg}$ of salinity, in a $600 \mathrm{~m}^{2}$ tank with a density of $100 \mathrm{~g} / \mathrm{m}^{2}$. Based on the size of the tank and its total biomass, the cultivation system was classified as intensive (Nicovita, 2002). The data collection process consisted of the simultaneous measurement of the four chosen physicochemical parameters. The study was carried out in an open pond, exposed to sunlight. The oxygen, temperature, and $\mathrm{pH}$ parameters were measured every day at 6 am and $3 \mathrm{pm}$ to capture their variability at two different times of day (morning and afternoon); transparency was measured at midday (12 pm), as this was considered to be the best time.

The oxygen, temperature, and $\mathrm{pH}$ parameters were measured using a portable multi-parameter meter. The transparency of the water was recorded using a $20 \mathrm{~cm}$ diameter Secchi disk, divided into quadrants painted alternately black and white, tied to a graduated rope.

The tilapia crop (Oreochromis mossambicus) was monitored for 21 weeks, and environmental parameters were recorded every day. In accordance with the objectives of the company, which intended to analyse the variability of the weekly aquatic environment in the Oreochromis mossambicus pond, the weekly averages and the respective standard deviations of each physicochemical parameter were calculated. This resulted in a set of 21 observations for each parameter, where each piece of data corresponded to the average of 14 observations measured in the respective week (for oxygen, temperature and $\mathrm{pH}$ ) and 7 observations for transparency. Therefore, the database was made up of four variables corresponding to the physicochemical para- meters and 21 observations, corresponding to the weeks of the cultivation process.

\section{MEWMA chart for autocorrelated processes}

The MEWMA control chart is considered to be a multivariate version of the EWMA (Exponentially Moving Average) chart proposed by Roberts (Roberts, 1959). The EWMA chart has the advantage of de- tecting small changes in the process compared to the Shewhart (Shewhart, 1931) chart, and its MEWMA multivariate version maintains this advantage respect to the Hotelling (Hotelling, 1947) chart. The first reference to the MEWMA chart is attributed to Lowry et al. (Lowry et al., 1992). The method consists of simultaneously controlling $m$ correlated variables through a control chart. The parameters of Lowry et al.'s (Lowry et al., 1992) MEWMA chart are calculated under the hypothesis of normality and independency between observations.

However, the time dependency of the environmental parameters in aquaculture cannot be avoided, and the process shows significant correlation and autocorrelation in the data.

Statistical methods have been developed to monitor multivariate and autocorrelated processes (Claro et al., 2007; Montgomery and Mastrangelo, 1991; Patel and Divecha, 2013; Testik, 2004). These methods are mainly based on two approaches: (1) fitting an adequate time series model for each process characteristic and adjusting a control chart for the obtained white noise (Claro et al., 2007; Montgomery and Mastrangelo, 
1991; Testik, 2004); (2) including the correlation structure in the calculation of the chart parameters and applying them in the multivariate chart (Patel and Divecha, 2013; Vasilopoulos and Stamboulis, 1978).

This paper is based on the first approach, where the MEWMA chart is adjusted to the white noise of the ARIMA (Autoregressive integrated moving average) model fitted to each environmental parameter. A good fit of the autocorrelation structure provides an ARIMA model with normal and independent residuals. Under these conditions, Lowry et al.'s (Lowry et al., 1992 MEWMA chart can be applied without any difficulty. Thus, it is assumed that any changes appearing in the residual chart could indicate that the process is out-of-control.

The MEWMA chart was adjusted as follows:

3.1 Adjusting an ARIMA model for each environmental parameter

Let $\mathrm{p} 1 \mathrm{t}, \mathrm{p} 2 \mathrm{t}, \mathrm{p} 3 \mathrm{t}, \ldots$, pmt denote $\mathrm{m}$ physicochemical parameters that characterise an aquatic environment in the aquaculture cultivation process. According to the characteristics of the aquaculture process, the $\mathrm{m}$ environmental parameters are expected to present a significantly correlated and autocorrelated structure. Thus, each parameter pit $(i=1, \ldots, m$ and $t=1, \ldots, n)$ is a time series and the corresponding method must be applied.

In the case studied the $p_{i t}$ value corresponded to the weekly mean of $(i=1, \ldots, m$ and $t=1, \ldots, n)$ is a time series and the corresponding method must be applied.

In the case studied the $p_{i t}$ value corresponded to the weekly mean of each physicochemical parameters, where $i=1,2,3,4$ represented the number of considered parameters and $t=1,2, \ldots, 21$ the weeks. For each $p_{i t}$ parameter, an ARIMA $(p, d, q)$ model was fitted with the following expression:

$\Phi_{\mathrm{p}}(\mathrm{B}) \nabla^{\mathrm{d}} \mathrm{p}_{\mathrm{it}}=\mathrm{c}+\Theta_{\mathrm{p}}(\mathrm{B}) \mathrm{a}_{\mathrm{it}}$

where:

$\Phi_{\mathrm{p}}(\mathrm{B})=1-\phi_{1} \mathrm{~B}-\phi_{2} \mathrm{~B}^{2}-\ldots-\phi_{\mathrm{p}} \mathrm{Bp} \Theta_{\mathrm{p}}(\mathrm{B})=1-\theta_{1} \mathrm{~B}-\theta_{2} \mathrm{~B}^{2}-\ldots-\theta_{\mathrm{q}} \mathrm{Bq}$

$\nabla^{d}=(1-B)^{d}$

$B$ is the delay operator; $d$ is the number of necessary differences to achieve stationarity in the mean, and; $a_{i t}$ is the white noise $\left(a_{i t} \sim N\left(0, \sigma^{2}\right)\right)$.

\subsection{Calculation of mean vector and covariance matrix of the white noise}

$m$ and $\sigma^{2}$ were considered as the respective mean and variance of the ARIMA white noise for the environmental parameter $\mathrm{i}$.

Then, for the four parameters $m=(0,0,0,0)$ and $\sigma^{2}=\left(\sigma_{1}{ }^{2}, \sigma^{2}, \sigma^{2}, \sigma^{2}\right)$ was obtained representing the mean and variance

vector, respectively. For a pair of parameters $\mathrm{i}$ and $\mathrm{j}$, the covariance between $a_{i t}$ and $a_{j t}$ can be estimated as:

$$
\widehat{\gamma}_{i, j}=\sum_{t=1}^{n} \frac{\left(a_{i t}\right)^{2}\left(a_{j t}\right)^{2}}{n-1}
$$

Then, the covariance matrix of the white noise $a_{i}$ and $a_{j}$ for the in- control process is:

$$
\Sigma_{\mathrm{a}}=\left(\begin{array}{llll}
\sigma_{1}^{2} & \hat{\gamma}_{1,2} & \hat{\gamma}_{1,3} & \hat{\gamma}_{1,4} \\
\hat{\gamma}_{2,1} & \sigma_{2}^{2} & \hat{\gamma}_{2,3} & \hat{\gamma}_{2,4} \\
\hat{\gamma}_{3,1} & \hat{\gamma}_{3,2} & \sigma_{3}^{2} & \hat{\gamma}_{3,4} \\
\hat{\gamma}_{4,1} & \hat{\gamma}_{4,2} & \hat{\gamma}_{4,3} & \sigma_{4}^{2}
\end{array}\right)
$$

3.3. Adjusting the MEWMA chart for the white noise 
Using the control chart proposed by Lowry et al. (Lowry et al., 1992) with the calculated parameters, the MEWMA chart for the ARIMA white noise was defined as:

$\vec{z} t=\Lambda \vec{a}_{t}+(1-\Lambda) \vec{z}_{t-1}$

Where

$$
\begin{aligned}
\Lambda & =\left(\begin{array}{cccc}
\lambda_{1} & 0 & \ldots & 0 \\
0 & \lambda_{2} & \ldots & 0 \\
0 & 0 & \lambda_{i} \ldots \\
0 & 0 & \ldots & \lambda_{m}
\end{array}\right) \\
\vec{z}_{0} & =\vec{m}=0 .
\end{aligned}
$$

and $0<\lambda_{i}<1(i=1, \ldots, 4) ; \vec{a}$ was the estimated vector means of the residual in each time $t ; \vec{m}$ was the in-control means process, as previously shown, all the elements were null for this vector.

The process is considered out-of-control if

$$
T_{t}^{2}=\vec{z}_{t}^{\prime} \Sigma_{\vec{z}_{t}}^{-1} \vec{z}_{t}>h_{2}
$$

where $h_{2}>0$ was the control limit and was calculated to obtain a specific in-control ARL. The covariance matrix of $z_{t}$ was calculated asymptotically as follows:

$$
\Sigma{\overrightarrow{z_{l}}}=\left(\frac{\lambda}{2-\lambda}\right) \Sigma_{a}
$$

assuming the equality of weights in the last observations for the $m$ variables $\left(\lambda_{1}=\ldots=\lambda_{4}=\lambda\right)$.

Multivariate process monitoring using an MEWMA chart consists of controlling process stability based on the $T^{2}$ statistic, assuming that the process is in-control if the value of this statistic is in the range [0,h2]. A process is considered to be stable if its parameter (mean and/or var-iance) does not change over time.

\subsection{Results and discussion}

Monitoring an aquatic environment in aquaculture seeks to verify the conformity of the parameters over time. Process conformity refers to the compliance of the established requirements of environmental parameters to ensure water quality.

In many aquaculture cultivation processes, only the conformity control of the environment parameters is prioritised. However, the process stability control is also important, as commented by Martinez (Martinez, 2006). Sudden changes of $5^{\circ} \mathrm{C}$ in the water temperature can cause fish to become stressed and they can sometimes die.

This work focuses on the monitoring of conformity as well as stability. Thus, the MEWMA chart shown above was applied to accomplish both aspects.

Fig. 1 shows the weekly means of the four parameters measured daily in the tilapia breeding process in the company Aquapesca de Mozambique. For each parameter, the theoretical limits used as an indicator of the conformity of water quality were considered (designated as Conformity Control Limit (CCL)), as suggested by Martinez (Martinez, 2006) and Alves and Mello (Alves and Mello, 2007); as was the statistical control limit (designated: Stability Control Limit $(\mathrm{SCL})$ ) calculated through the X-bar chart method developed by Shewhart (Shewhart, 1931):

$$
\overline{\bar{x}} \pm L \sigma
$$

where $\mathrm{x}$ is the general mean (in this case, it is the mean of the weekly mean values of each environmental parameter) of the variable $\mathrm{x}$; $\sigma$ is the standard deviation of variable $\mathrm{x}$; and $\mathrm{L}=3$ (to comply with the 3-sigma rule). 

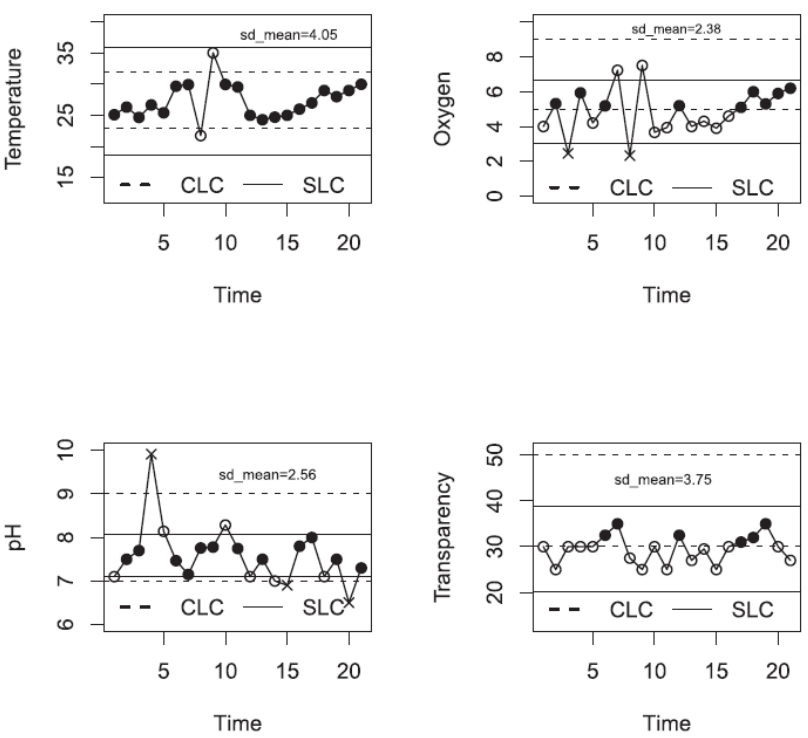

Fig. 1. Environment parameters.

The caption shows the meaning of the symbols used in the Fig. 1. Observations with the symbol ( $)$ are those that complied with both the conformity and stability requirements; $(0)$ indicates that the observation failed one requirement; and $(x)$ corresponds to observations that did not comply with either requirement.

Therefore, the observations 3 , and 8, and 4, 15 and 20 did not comply with conformity and stability in oxygen and $\mathrm{pH}$, respectively. Considering that the process is in-control if all observations comply with the conformity and stability requirements for each parameter, only the observations 6,12 and 16 were shown to be in-control.

This univariate method becomes complex for processes with many parameters, since the state of the process is verified by the condition for each parameter. Using this method, the relevant information provided by the correlation structure between parameters is not controlled.

This research is focused on the multivariate method, and we defend that the overall state of a multivariate process should not be evaluated solely on the non-compliance of the requirements of each variable. Therefore, a MEWMA chart for the ARIMA white noise was adjusted to monitor the joint variability of the environmental parameters.

The multivariate method started by fitting an ARIMA model to each environmental parameter. Through simple and partial correlation functions (Fig. 2), AIC and BIC statistics, and the AR(1), a model was identified and estimated for the four environmental parameters. The obtained residual was tested (Ljung-Box test, simple and partial correlations function) and it was verified that, at a significance level of $5 \%$, the noise of the models was normal and independent.
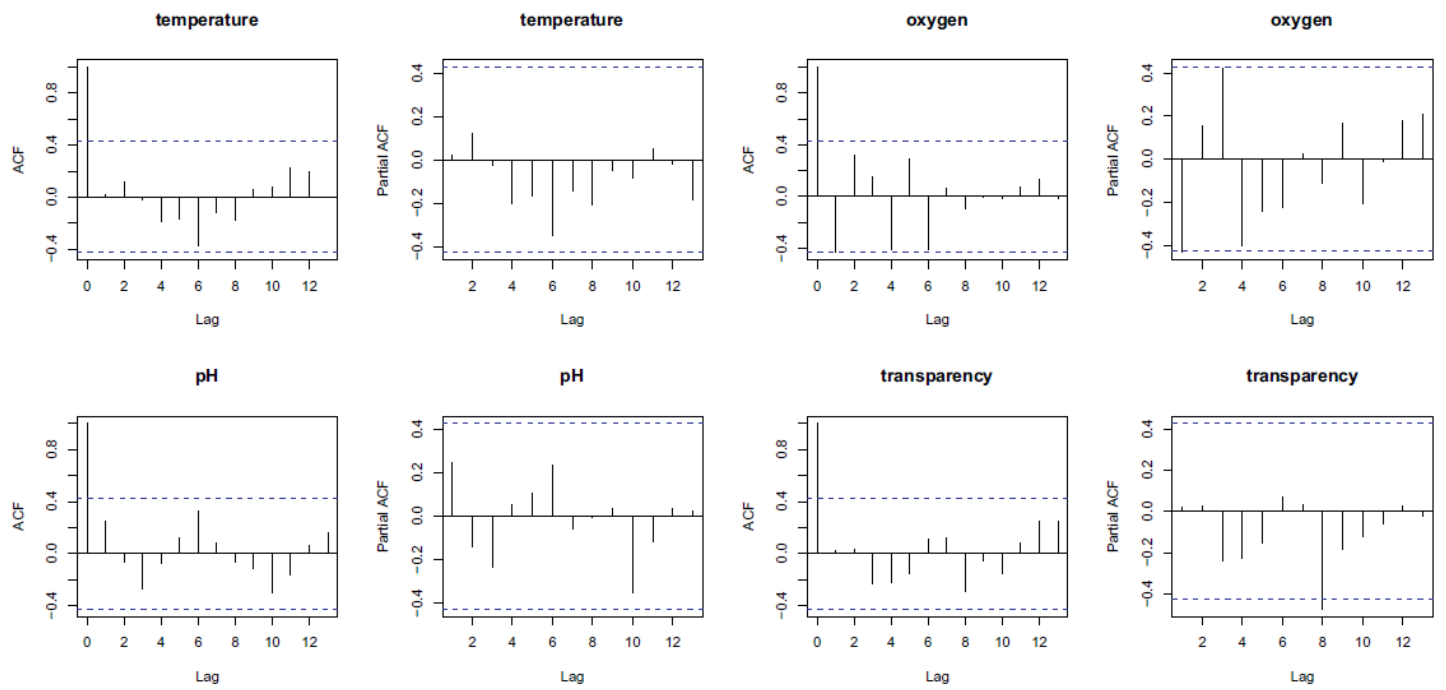

Fig. 2. simple and partial function of the parameters. 
To adjust the MEWMA chart for the ARIMA white noise, the mean vector $m$

$$
-\vec{m}=(0,0,0,0)
$$

and the covariance matrix:

$$
\Sigma_{\mathrm{a}}=\left(\begin{array}{cccc}
8.317 & 1.889 & -0.154 & -0.934 \\
1.889 & 2.034 & -0.027 & 1.678 \\
-0.154 & -0.027 & 0.636 & -0.080 \\
-0.934 & 1.678 & -0.080 & 13.254
\end{array}\right)
$$

were calculated, and then were determined using expression (4) and (5) statistics $\vec{z} t$ and $\mathrm{T}^{2}$.

The control limit $h_{2}$ (stability control limit) was calculated applying the Markov chain method used by Patel and Devicha (Patel and Divecha, 2013) and, by Lucas and Saccucci (Lucas and Saccucci, 1990) for the ARL (Average Run Length) calculation. In this work, an in-control ARL equal to $370(A R L(d=0)=$ 370) was considered, meaning that 370 samples would be necessary to detect a false alarm in the process. This considered in-control ARL corresponds to a false alarm probability of $\alpha=1-p(i, 0)=$ 0.0027 , where $p(i, 0)$ is the probability that the observation is kept under control when moving to another state. The conformity control limits were determined as follows:

$$
C C L_{i}=\vec{z}_{i}^{\prime} \Sigma \vec{z}_{i}
$$

and

$$
C C L_{s}=\vec{z}_{s}^{\prime} \Sigma \vec{z}_{s}
$$

where the vectors $i=(23,5,7,30)$ and $s=(32,9,9,50)$ were composed of the minimum and maximum aquaculture tolerance limits for temperature, oxygen, $\mathrm{pH}$ and transparency, respectively.

Therefore, process conformity was considered when

$C C L_{i}<T^{2}<C C L_{s}$

Table 1 shows the numerical results corresponding to the $z_{t}$ and $\mathrm{T}^{2}$ statistics for the 21 observations (weeks)

\begin{tabular}{|c|c|c|c|c|c|}
\hline \multirow[t]{3}{*}{ Time } & \multicolumn{4}{|c|}{ MEWMA residual vector } & \multirow{3}{*}{$\begin{array}{l}\text { MEWMA statistic } \\
\text { T2 }\end{array}$} \\
\hline & \multicolumn{4}{|c|}{$\mathrm{h} 2=520,18 \mathrm{SCLi}=314,95 \mathrm{SCL}=1000,08$} & \\
\hline & $\mathrm{z} 1$ & $\mathrm{z} 2$ & $\mathrm{z} 3$ & $\mathrm{z} 4$ & \\
\hline 1 & 28,18 & 4,54 & 7,81 & 32,90 & 351,86 \\
\hline 2 & 30,31 & 7,11 & 8,54 & 22,61 & $309,51^{*}$ \\
\hline 3 & 26,60 & 1,22 & 8,84 & 32,85 & 408,04 \\
\hline 4 & 30,42 & 8,30 & 13,15 & 32,57 & $532,47^{*}$ \\
\hline 5 & 27,53 & 4,59 & 9,28 & 32,31 & 384,20 \\
\hline 6 & 35,84 & 6,53 & 7,82 & 37,08 & 451,07 \\
\hline 7 & 35,77 & 10,48 & 7,15 & 41,62 & 432,43 \\
\hline 8 & 18,76 & 0,34 & 8,37 & 25,96 & $279,33^{*}$ \\
\hline 9 & 45,71 & 10,91 & 8,35 & 21,11 & 452,68 \\
\hline 10 & 34,47 & 2,88 & 9,30 & 31,50 & 483,73 \\
\hline 11 & 33,20 & 3,50 & 8,13 & 21,35 & 353,84 \\
\hline 12 & 23,71 & 6,07 & 6,79 & 36,72 & $295,60^{*}$ \\
\hline 13 & 22,44 & 3,59 & 7,62 & 25,29 & $252,07^{*}$ \\
\hline 14 & 23,43 & 4,23 & 6,61 & 30,47 & $261,30^{*}$ \\
\hline 15 & 24,15 & 3,43 & 6,45 & 21,37 & $218,30^{*}$ \\
\hline 16 & 26,24 & 4,88 & 8,29 & 31,73 & 333,91 \\
\hline 17 & 28,21 & 5,85 & 8,64 & 33,56 & 367,71 \\
\hline 18 & 32,09 & 7,58 & 6,78 & 35,30 & 355,15 \\
\hline 19 & 29,78 & 6,02 & 7,61 & 40,97 & 411,33 \\
\hline 20 & 31,60 & 7,15 & 5,60 & 30,38 & $292,96^{*}$ \\
\hline 21 & 33,34 & 7,62 & 7,29 & 24,34 & $311,53^{*}$ \\
\hline
\end{tabular}
considered. The $\mathrm{T}^{2}$ values marked with $\left({ }^{*}\right)$ correspond to the abovementioned out-of-control observation.

Table 1

Numerical results.

* Out-of-control. 
The resulting MEWMA chart adjusted for the ARIMA white noise is shown in Fig. 3, in which the aquatic environment was monitored using the four physicochemical parameters simultaneously. Both conformity and stability were considered. The $T^{2}$ statistic is an indicator of the overall variability of the aquatic environment denoted by these para- meters. The MEWMA chart shows that more than half of the observations of the process verified both the stability and conformity requirements. The observations $2,4,8,12,13,14,15,20$ and 21 did not verify both requirements, and thus were considered out-of-control.

The proposed multivariate method for monitoring an aquatic environment in aquaculture consisted of applying the MEWMA chart shown in Fig. 3. However, the univariate charts are still relevant. In the cases where the MEWMA chart indicated out-of-control observations, univariate charts were used to identify which parameter caused the anomaly. In this specific case, this shows that the $\mathrm{pH}$ caused the non- conformity of the stability of observation 4 . The non-conformity of

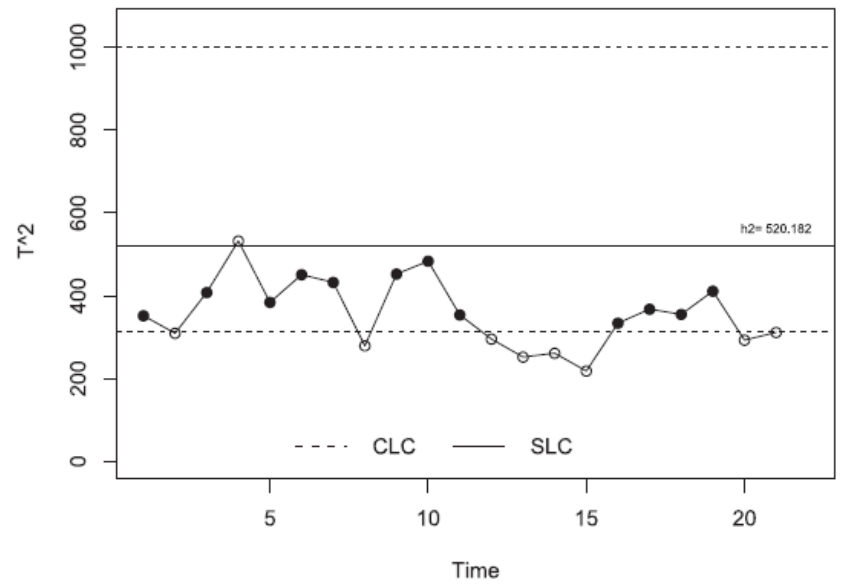

Fig. 3. Monitoring process using MEWMA chart.

observation 8 was caused by temperature and oxygen; and the levels of oxygen, $\mathrm{pH}$ and transparency contributed to the uncontrolled environment in observations 2,12,13,14,15,20 and 21 .

The observations 1,3,5,9,10,11 were marked as being out-of-control in the univariate method; however, the multivariate method shows they were within both control limits ( $\mathrm{SCL}$ and $\mathrm{CCL}$ ). These observations are considered to be false alarms (type I error). On the other hand, observation 12 complied with the conformity requirement for all environmental parameters; however, it was not verified in the MEWMA chart, indicating that the univariate method could not identify the process failure caused by the correlation of the parameters (type II error).

Therefore, the inclusion of joint parameter information and the control of both stability and conformity must be carried out in order to signal anomalies in the process, avoiding the mentioned errors, and to ensure a good aquatic environment in the cultivation of aquatic species in aquaculture.

\section{Conclusions}

This paper has discussed the issues that occur when monitoring a multivariate process using univariate methods. Thus, the study was oriented towards the analysis of the adequacy of a statistical method in the data structure of aquaculture. Therefore, the MEWMA chart was adjusted for the white noise of the ARIMA model fitted to four parameters selected to characterise the aquatic environment in cultivation tanks in the company Aquapesca de Mozambique.

Monitoring was performed using the proposed multivariate statis- tical method to control both the conformity and the stability of the process. The results showed that the aquatic environment was often outof-control. However, most of the observations indicated by the univariate method corresponded to false alarms. The multivariate control method based on the MEWMA chart was adjusted to the data structure of the observed aquatic environment in aquaculture, and the correlation and autocorrelation in the parameters was modelled. Nevertheless, the proposed multivariate method was shown to be more consistent when controlling the conformity and stability of an aquatic environment. Therefore, it can be considered an efficient methodology for monitoring aquatic environments in aquaculture. 


\section{References}

- $\quad$ Alves, S., Mello, L., 2007. Manual para Monitoramento Hidrobiologico em Fazendas de cultivo de camarão. Recife 1 (1), 1-58.

- $\quad$ Claro, F., Costa, A.F.B., Machado, M., 2007. Ewma and control charts for the monitoring of autocorrelated processes. PRO, vol. 17 (3), 536-546 (Set./Dez).

- Hotelling, H., 1947. Multivariate quality control. In: Eisenhart, C., Hastay, M.W., Wallis, W.A. (Eds.), Techniques of Statistical Analysis. McGraw-Hill, New York.

- Jinfeng, L., Shun, C., 2015. A Zigbee-Based Aquiculture Water Quality Monitoring System. International Journal of $u$ - and e- Service, Science and Technology.

- $\quad$ Liu, X., Chen, H., Zhu, C., 2016. Design of Self-Learning Cruising Type Water Quality Monitoring System Based on gps. Chinese Society of Agricultural Engineering.

- $\quad$ Lowry, C.A., Woodall, W.H., Champ, C.W., Rigdon, S.E., 1992. A multivariate ex- ponentially weighted moving average control chart. Technometrics 34, 46-53.

- Lucas, J., Saccucci, M., 1990. Exponentially weighted moving average control schemes: properties and enhancements. Technometrics 32 (1), 1-29.

- $\quad$ Lucas, J., Southgate, P., 2003. Aquaculture Farming Aquatic Animals and Plants. Fishing News Books. Blackwell Pblishing, lowa, USA, pp. 328.

- Martinez, M., 2006. Manejo del Cultivo de Tilapia. University of Hawai'i.

- Martínez, I. Giménez, A., Oliver, N. \& J. G. Análisis de parámetros físicos, químicos y biológicos en las aguas costeras de la región de Murcia. III Jornadas de Introducciêşn a la Investigacón de la UPCT.

- Montgomery, D., Mastrangelo, C., 1991. Some statistical process control methods for autocorrelated data. J. Qual. Technol., vol. 23, 179-193.

- $\quad$ Nicovita, 2002. Manual de Crianza de Tilapia. Disponible en. http://www.nicovita. com.pe.

- $\quad$ Patel, A., Divecha, J., 2013. Modified MEWMA Control Scheme for an Analytical Process Data. Volume 13 Issue 3 Version 1.0. Global Journals Inc., USA.

- $\quad$ Roberts, S., 1959. Control chart tests based on geometric moving average. Technometrics 239-250.

- $\quad$ Russell, D., Thuesen, P., Thomson, F.E., 2012. A review of the biology, ecology, dis- tribution and control of mozambique tilapia, Oreochromis mossambicus (peters 1852) (pisces: Cichlidae) with particular emphasis on invasive australian populations. Rev. Fish Biol. Fish. 22, 533-554.

- Shewhart, W.A., 1931. Economic Control of Quality of Manufactured Product. D. Van Nostrand Co., Inc, New York.

- $\quad$ Testik, M., 2004. Model Inadequacy and Residuals Control Charts for Autocorrelated Processes. Wiley InterScience.

- Vasilopoulos, A., Stamboulis, P., 1978. Modification of control chart limits in the presence of data correlation. J. Qual. Technol. 1 (1), 20-30.

- Xu, H., Zhang, Y., 2014. Aquiculture remote monitoring system based on android plat- form. In: International Conference on Green Materials and Environmental Engineering, GMEE 2014; Hong Kong; China; Code 110619, pp. 956-961.

- $\quad$ Yan, B., Shi, P., 2014. Intelligent monitoring system for aquiculture based on internet of things. Nongye Jixie Xuebao. Transactions of the Chinese Society for Agricultural Machinery vol.45, 259-265.

- Zhou, L., Xing, Y., 2013. Intelligent aquaculture monitoring system based on fieldbus. In: International Conference on Materials Science, Machinery and Energy Engineering, MSMEE.

- Zhou, R., Qin, X., Peng, S., Shi, H., Deng, S., 2014. Macroinvertebrate investigation and their relation to environmental factors in Bohai Bay. Shengtai Xuebao. Acta Ecol. Sin., vol. 34, 50-58. 